\title{
Calculations of the complex network's steady-state modes by brining it to equivalent open
}

\author{
Dauren Akhmetbayev ${ }^{1}$, Assemgul Zhantlessova ${ }^{* 1}$, Arman Akhmetbayev ${ }^{2}$ \\ ${ }^{1}$ Power Supply Department, S.Seifullin Kazakh Agrotechnical University, Kazakhstan \\ ${ }^{2}$ Direction of Information Systems of JSC Kaztelecom, Kazakhstan
}

\begin{abstract}
The paper considers the development of the idea of diakoptics as applied to the calculation of the steady-state modes of energy system's complex electrical networks. The well-known goal of diakoptics is to obtain the equations of state for the dedicated part of the system, the study of which is much simpler than the study of the initial system and can be achieved by improving its steady state equations. Technique for dividing a complex-closed system into a set of uncomplicated subsystems was developed based on the inverse form of nodal equations. Analytic expressions for the intersection circuits obtained based on identical equality of voltage at the nodes of the system division into subsystems are proposed. Using the example of $110 \mathrm{kV}$ network calculation, the technique for determining the matrixes of generalized parameters of the dedicated subsystems, the sizes of which depend on the number of their broken link is shown. Analytical determination of the equality condition of the voltage of subsystems intersections nodes, allowed analyzing a complex closed network by bringing it to an equivalent open.
\end{abstract}

\section{Introduction}

The essence of the method of diakoptics is to solve tasks with a large number of variables in parts, by which properties the basic characteristics of the original system get restored.

Each subsystem, determined using the unmating method is analysed and calculated separately, then a solution for the entire system is determined based on tensors of the partial solutions joints [1].

As a result of the initial system unmating, an additional system- circuits of intersections is formed. All the parameters arising because of separation are collected in this system. Through the circuit of intersections, a link is established between old and new parameters using the coupling equations. Moreover, each subsystem, which research is much simpler than the research of the original system, is analysed separately, then the particular solutions are joined step by step until a solution of the original system is obtained $[2,3]$.

In some works [4, 5], in the process of iterations, in addition to the matrixes of generalized parameters for individual subsystems, there are also matrixes the order of which determined by the number of boundary nodes of the entire set of subsystems can be very high. Standard methods of forming matrixes of generalized parameters that cannot be determined directly by the scheme are practically unacceptable because of the excessively large volume of computations [6]. Applying the properties of matrix math, for example, dividing matrixes into blocks can significantly reduce the amount of the computational process. In this case, the inversion of a single matrix of large order is replaced by the inversion of several matrixes of lower order, which leads to a significant reduction in the number of computational operations. However, the recalculation of the matrixes of the generalized parameters of the subsystems, corresponding to the restoration of broken links remains complicated. These shortcomings were overcome by the development of the method of diakoptics by a number of authors $[7,8]$.

For the first time, it was suggested that the schemes be cut by nodes, and not by branches, preserving all branches of the scheme. At the same time subsystems were allocated in such a way that they were connected in series, forming a highway or radial circuit connected to the slack node.

This approach made it possible to form subsystems of approximately similar sizes, by increasing the necessary number of sub graphs of the initial system graph. At each step of the computational process, equivalent matrixes of generalized system parameters are used. They have a low order, corresponding to the sizes of individual subsystems, and the matrix is calculated only once at the stage of formation of conditionally constant information. One of the main advantages of the above approach is the provision of a favourable convergence condition for the computational process, since the links between the subsystems are not violated at any stage of this process [9-11].

The approach developed below is fundamentally different in that the network nodal voltages determined, as a result of individual calculation of individual subsystems, will be as they would be at the boundaries 
of broken links without dividing into parts of the original system. Such an approach can be implemented on the basis of the inverse form of the nodal voltage equations.

\section{Inverse form of the nodal voltage equations}

By transforming the known equations of state of arbitrary complexity electrical networks, we obtain a matrix equation for the nodal voltage drops with respect to the matrix of driving currents distribution coefficients, which has the following form [11-13].

$$
\dot{\mathrm{U}}_{\mathrm{D}}=\underline{\mathrm{C}}^{\mathrm{t}} \underline{\mathrm{Z}}_{\mathrm{b}} \underline{\mathrm{C}} \text {, }
$$

where $\underline{C}$ - rectangular matrix of a complex of current distribution coefficients; $\underline{Z}_{b}$ - diagonal matrix of the complex of scheme branches resistances;

$\mathrm{J}$ - column matrix of the complex of driving currents; $\mathrm{t}$ matrix transposition sign.

The matrix of current distribution coefficients is determined based on all trees of the directed graph of a complex electrical network, and is used as initial data for calculating its steady-state modes [14-16].

\section{Conditions for the equality of the subsystems intersections voltage nodes}

Complex-closed circuit can be reduced to an open form by cutting the nodes. The choice of the node-cutting place can be arbitrary, the main thing is that all contours are destroyed and the resulting open circuits remain connected to the basic node. The advantage of the proposed approach is that to obtain open networks it is necessary to break considerably fewer links, since cutting one node can replace the cutting of several branches incident to this node.

The conditions for the equivalence of the response of the original complex scheme and the open sub schemes at the nodes of their intersections can be established based on the multiport network shown in Fig. 1.

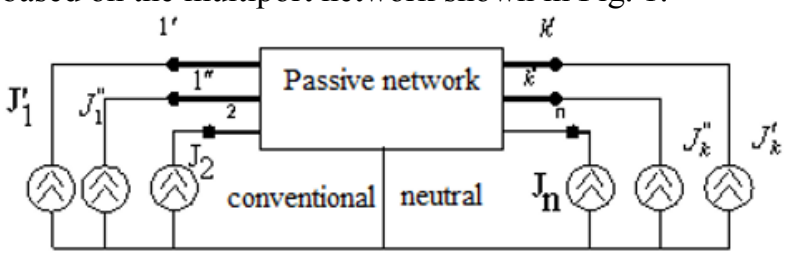

Fig. 1. Multiport network.

Suppose that, as a result of cutting the first k-nodes, a branched open circuit is obtained, where each cut point is replaced by two fictious-points provided with additional indexes (" and "). Thus, the original complex system is divided into two subsystems consisting of an open circuits' scheme.

The relationship between the initial and new disturbances at the intersections nodes of the subsystems is established based on the first Kirchhoff law, which will be written in the matrix format in the form:

$$
\dot{\mathrm{J}}^{\prime}+\dot{\mathrm{J}}^{\prime \prime}=\dot{\mathrm{J}}_{\mathrm{p}}
$$

New circuit responses at the subsystems intersections nodes are determined based on position principle, in the form of a sum of subsystems responses caused by new disturbances applied to the subsystems intersections nodes and disturbances of the subsystem applied to uncut nodes, which are calculated on the basis of matrix equations:

$$
\begin{aligned}
& \dot{\mathrm{U}}_{\Delta}^{\prime}=\left\|\underline{\mathrm{C}}_{\mathrm{p}}{ }^{\mathrm{t}} \underline{\mathrm{Z}}_{\mathrm{b}} \underline{\mathrm{C}}_{\mathrm{p}}\right\| \cdot\left\|^{\prime} \dot{\mathrm{J}}^{\prime}+\right\| \underline{\mathrm{C}}_{\mathrm{p}}{ }^{\mathrm{t}} \underline{\mathrm{Z}}_{\mathrm{b}} \underline{\mathrm{C}}_{\mathrm{n}} \| \cdot \cdot \dot{\mathrm{J}}_{\mathrm{n}}, \\
& \dot{\mathrm{U}}_{\Delta}{ }^{\prime \prime}=\left\|\underline{\mathrm{C}}_{\mathrm{p}}{ }^{\mathrm{t}} \underline{\mathrm{Z}}_{\mathrm{b}} \underline{\mathrm{C}}_{\mathrm{p}}\right\|^{\prime \prime} \dot{\mathrm{J}}^{\prime \prime}+\left\|\underline{\mathrm{C}}_{\mathrm{p}}{ }^{\mathrm{t}} \underline{\mathrm{Z}}_{\mathrm{b}} \underline{\mathrm{C}}_{\mathrm{n}}\right\|^{\prime \prime} \dot{\mathrm{J}}_{\mathrm{n}},
\end{aligned}
$$

where $\dot{\mathbf{J}}^{\prime}, \dot{J}^{\prime \prime}$ - column matrixes of fictitious currents applied to subsystems intersections nodes; $\dot{\mathrm{J}}_{\mathrm{n}}^{\prime}, \dot{\mathrm{J}}_{\mathrm{n}}{ }_{\mathrm{n}}$ - column matrixes of driving currents, uncut nodes of subsystems; $\underline{C}_{p}^{\prime}, \underline{C}_{p}^{n}$ - matrixes of distribution coefficients of fictitious nodal currents of subsystems; $\underline{\mathrm{C}}_{\mathrm{n}}^{\prime}, \underline{\mathrm{C}}_{\mathrm{n}}^{\mathrm{n}}$ - matrixes of current distribution coefficients of the subsystems uncut nodes; $\underline{Z}_{b}^{\prime}, \underline{Z}_{b}^{*}$ - diagonal matrix of the branches of the corresponding subsystems; $\left\|\underline{C}_{\mathrm{p}}{ }^{{ }^{t}} \underline{Z}_{\mathrm{b}} \underline{\mathrm{C}}_{\mathrm{p}}\right\|^{*},\left\|\underline{\mathrm{C}}_{\mathrm{p}}{ }^{\mathrm{t}} \underline{\mathrm{Z}}_{\mathrm{b}} \underline{\mathrm{C}}_{\mathrm{p}}\right\|^{*}$ - matrixes of the system functions of resistance with respect to the subsystems intersections nodes; $\left\|\underline{C}_{\mathrm{p}}{ }^{\mathrm{t}} \underline{\mathrm{Z}}_{\mathrm{b}} \underline{\mathrm{C}}_{\mathrm{n}}\right\|^{t},\left\|\underline{\mathrm{C}}_{\mathrm{p}}{ }^{\mathrm{t}} \underline{\mathrm{Z}}_{\mathrm{b}} \underline{\mathrm{C}}_{\mathrm{n}}\right\|^{*}$ - matrixes of system resistance functions with respect to the subsystems uncut nodes.

Response of the circuit of open subsystems intersections will be equivalent to the response of the initial system circuit at the equality of voltage vectors at the subsystems intersections nodes obtained as a result of traversing different branches:

$$
\dot{\mathrm{U}}_{\Delta}^{\prime}=\dot{\mathrm{U}}_{\Delta}{ }_{\Delta}
$$

equating the right-hand parts (3), (4):

$$
\begin{gathered}
\left\|\underline{C}_{\mathrm{p}}{ }^{{ }^{t}} \underline{\mathrm{Z}}_{\mathrm{b}} \underline{\mathrm{C}}_{\mathrm{H}}\right\|^{\prime \prime} \dot{\mathrm{J}}_{\mathrm{n}}{ }^{\prime \prime}-\left\|\underline{\mathrm{C}}_{\mathrm{p}}{ }^{\mathrm{t}} \underline{\mathrm{Z}}_{\mathrm{b}} \underline{\mathrm{C}}_{\mathrm{n}}\right\|^{\prime} \mathrm{j}_{\mathrm{n}}^{\prime}= \\
=\left\|\underline{\mathrm{C}}_{\mathrm{p}}{ }^{\mathrm{t}} \underline{\mathrm{Z}}_{\mathrm{b}} \underline{\mathrm{C}}_{\mathrm{p}}\right\|^{\prime} \dot{\mathrm{J}}^{\prime}-\left\|\underline{\mathrm{C}}_{\mathrm{p}}{ }^{\mathrm{t}} \underline{\mathrm{Z}}_{\mathrm{b}} \underline{\mathrm{C}}_{\mathrm{p}}\right\|^{\prime \prime} \dot{\mathrm{J}}^{\prime \prime}
\end{gathered}
$$

or

$$
\left\|\underline{C}_{p}{ }^{t} \underline{Z}_{b} \underline{C}_{p}\right\|^{t} \dot{J}^{\prime}-\left\|\underline{C}_{p}{ }^{t} \underline{Z}_{b} \underline{C}_{p}\right\|^{*} \dot{J}^{\prime \prime}=\dot{U}_{\Delta n}^{\prime \prime}{ }^{\prime},
$$

where $\dot{U}_{\Delta \mathrm{n}}^{n-'}=\mathrm{U}_{\Delta \mathrm{n}}-\dot{\mathrm{U}}_{\Delta \mathrm{n}}^{\prime}$ - algebraic difference of nodal voltages drops caused by currents of uncut nodes of subsystems; $\dot{U}_{\Delta \mathrm{n}}^{\prime}=\left\|\underline{\mathrm{C}}_{\mathrm{p}}{ }^{\mathrm{t}} \underline{\mathrm{Z}}_{\mathrm{b}} \underline{\mathrm{C}}_{\mathrm{H}}\right\| \cdot \|^{\prime} \dot{\mathrm{J}}_{\mathrm{n}}^{\prime}$ - nodal voltage drops caused by currents of uncut nodes of the subsystem with the index ('); $\dot{U}^{\prime \prime}{ }_{\Delta \mathrm{n}}=\left\|\underline{\mathrm{C}}_{\mathrm{p}}{ }^{\mathrm{t}} \underline{\mathrm{Z}}_{\mathrm{b}} \underline{\mathrm{C}}_{\mathrm{n}}\right\| " \mathrm{~J}_{\mathrm{n}}^{n}$ the same, the subsystem with the index ("). 
Determination of the equivalence conditions for the responses of the initial system and the systems obtained as a result of cutting the nodes reduces to determining new disturbances that satisfy the equalities of the responses of the subsystems relative to the nodes of their intersections. For this purpose, we make up a system of matrix equations (2) and (6):

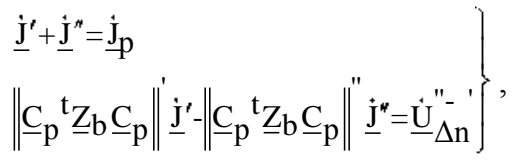

where the required parameters are new distributions, $\underline{\mathbf{J}}^{\prime}, \underline{\mathbf{J}}^{\prime}$ applied to the subsystems intersections nodes.

The system (7) can be written in the form of a matrix equation:

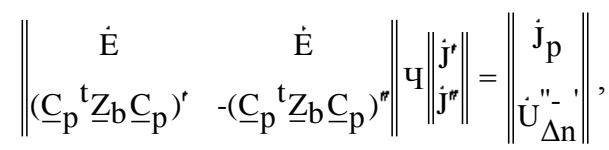

where $\dot{\mathbf{E}}$ is the unity diagonal matrix;

$\left\|\begin{array}{cc}\dot{\mathrm{E}} & \dot{\mathrm{E}} \\ \left(\underline{\mathrm{C}}_{\mathrm{p}}{ }^{\mathrm{t}} \underline{\mathrm{Z}}_{\mathrm{b}} \underline{\mathrm{C}}_{\mathrm{p}}\right)^{\prime} & -\left(\underline{\mathrm{C}}_{\mathrm{p}}{ }^{\mathrm{t}} \underline{\mathrm{Z}}_{\mathrm{b}} \underline{\mathrm{C}}_{\mathrm{p}}\right)^{\prime \prime}\end{array}\right\|-\quad$ a square, nonsingular matrix of the size that is equal to the number of fictitious nodes of intersections circuit.

Then the solution (8) is written as:

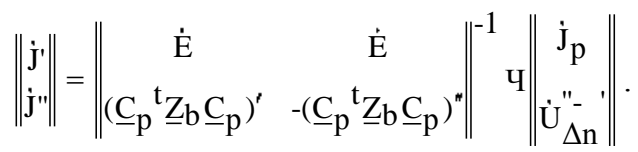

If we use the properties of partitioning the matrixes into blocks, then the solution of system (6) can be substantially simplified by eliminating $\underline{J}^{\prime}$ variables. After simple transformations, the system (7) reduces to the form:

$$
\underline{Z J^{\prime \prime}}=\dot{U}_{\Delta \Sigma},
$$

where

$\underline{Z}=-\left(\left\|\underline{C}_{p}{ }^{t} \underline{Z}_{b} \underline{C}_{p}\right\| "+\left\|\underline{C}_{p}{ }^{t} \underline{Z}_{b} \underline{C}_{p}\right\|\right.$ ') - square, nonsingular matrix of the size that is equal to the number of nodes of the original system intersections circuit;

$\dot{\mathrm{U}}_{\Delta \Sigma}=\left(\dot{\mathrm{U}}_{\Delta \mathrm{n}}{ }^{\prime-}-\left\|\underline{\mathrm{C}}_{\mathrm{p}}{ }^{\mathrm{t}} \underline{\underline{Z}}_{\mathrm{b}} \underline{\mathrm{C}}_{\mathrm{p}}\right\| \cdot \dot{\mathrm{J}}_{\mathrm{p}}\right)$ - column matrix of fictitious nodal voltage drops.

The solution of the matrix equation (10)

$$
\dot{\mathrm{J}}^{\prime \prime}=\underline{\mathrm{Z}}^{-1} \dot{\mathrm{U}}_{\Delta \Sigma},
$$

is simpler relatively to $\underline{J}^{\prime \prime}$ than the solution of the matrix equation (9).
To solve (11), we need to calculate the inverse matrix $\underline{\mathbf{z}}^{-1}$, the size of which is equal to the number of cut nodes, which requires less labor than determining the inverse matrix in expression (9).

The values of the remaining desirable variables are determined by the formula:

$$
\dot{J}^{\prime}=\dot{J}-\dot{J}^{n},
$$

After determining the fictitious currents of all the subsystems intersections nodes, we can investigate the behavior of the initial system based on the modes of the dedicated subsystems.

In the general case, the source scheme can be divided into $\mathrm{n}$ subsystems. Then, to determine fictitious currents at the nodes of their intersections, the following expression is true:

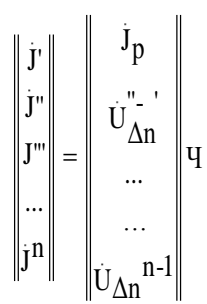

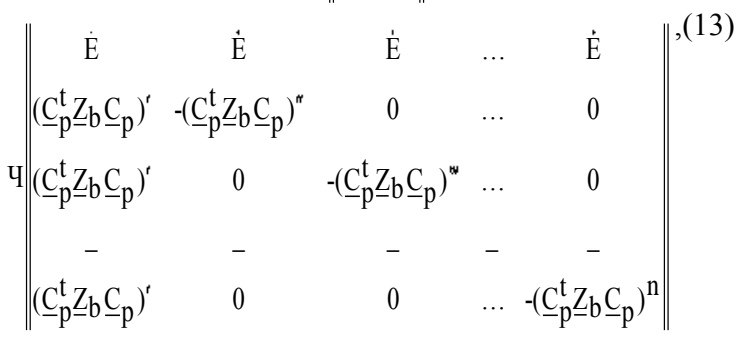

where

$\dot{\mathrm{U}}_{\Delta \mathrm{n}}^{\mathrm{n}-1}=\dot{\mathrm{U}}_{\Delta \mathrm{n}}^{\mathrm{n}}-\dot{\mathrm{U}}_{\Delta \mathrm{n}}^{\prime}=\left\|\underline{\mathrm{C}}_{\mathrm{p}}^{\mathrm{t}} \underline{\mathrm{Z}}_{\mathrm{b}} \underline{\mathrm{C}}_{\mathrm{n}}\right\|^{\mathrm{n}}{ }_{\mathrm{U}}^{\mathrm{J}}{ }_{\mathrm{n}}^{\mathrm{n}}-\left\|\underline{C}_{\mathrm{p}}^{\mathrm{t}} \underline{\mathrm{Z}}_{\mathrm{b}} \underline{\mathrm{C}}_{\mathrm{n}}\right\| \cdot \cdot \dot{\mathrm{J}}_{\mathrm{n}}^{\prime} \quad-$ algebraic difference of nodal voltage drops caused by the currents of uncut nodes of the corresponding subsystems.

\section{Calculation of a complex network by bringing it to equivalent open}

As an example, we will consider the design diagram of the $110 \mathrm{kV}$ electric network shown in the figure 2. c задающими токами: $\quad \dot{\mathrm{J}}_{1}=0.16+0,05 \mathrm{i} ; \mathrm{J}_{2}=0.27+0,05 \mathrm{i}$; $\mathrm{J}_{3}=6+4,2 \mathrm{i}$.

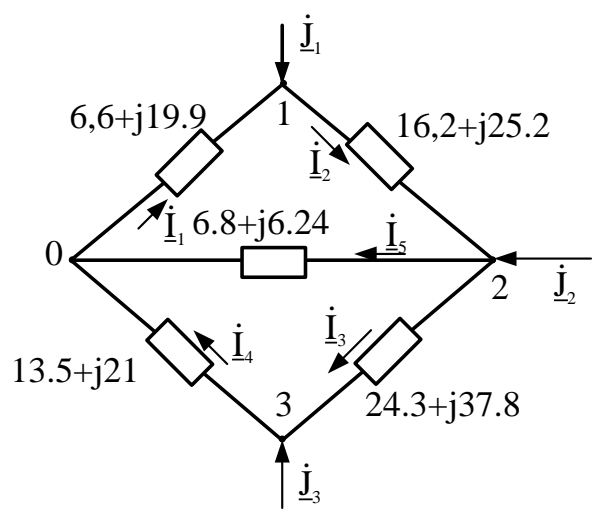




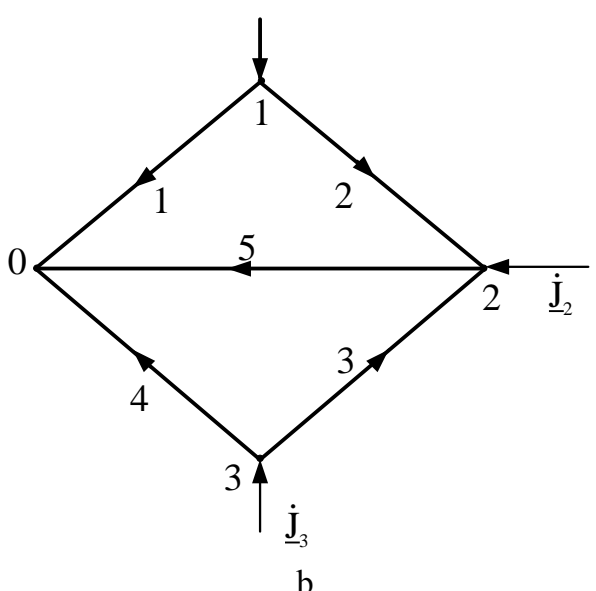

Fig. 2. The design diagram (a) and the directed graph of the $110 \mathrm{kV}$ network (b).

As a result of cutting the nodes at points 1,3 , a branched, open network graph shown in Fig. 3 was obtained

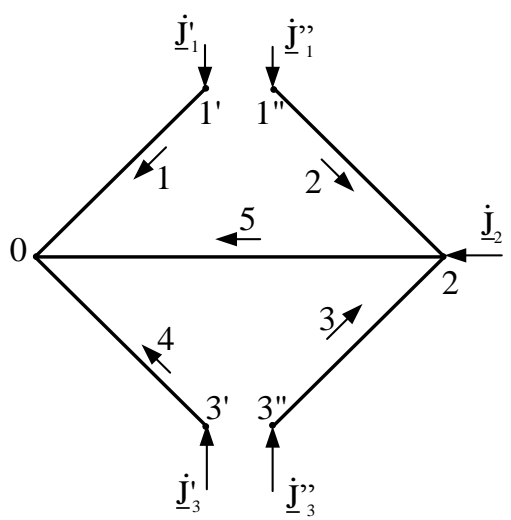

Fig. 3. Graph of open sub schemes (') and (").

Each cutting point is replaced by two fictitious points, provided with additional indices (' and "). The driving nodal currents at fictitious points are arbitrarily redistributed under the condition:

$$
\left.\begin{array}{l}
\dot{J}_{1}^{\prime}+\dot{J}_{1}^{\prime \prime}=\dot{J}_{1} \\
\dot{J}_{3}^{\prime}+\dot{J}_{3}=\dot{J}_{3}
\end{array}\right\}
$$

The modes of the open circuits will be equivalent to the regime of a complex-closed circuit subject to identity:

$$
\left.\begin{array}{l}
\dot{\mathrm{U}}_{\Delta 1}=\dot{\mathrm{U}}{ }^{\prime \prime} \Delta 1 \\
\dot{\mathrm{U}}_{\Delta 3}=\dot{\mathrm{U}}^{\prime \prime} \Delta 3
\end{array}\right\},
$$

The values of the fictitious currents (14) ensuring the identity conditions (15) are determined on the basis of the matrix equation (7), which in the open form is written in the following form:

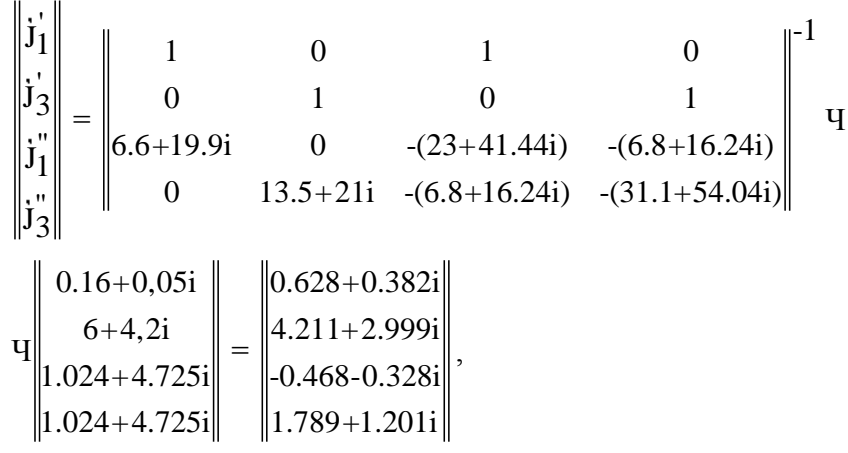

where $\underline{\dot{\mathbf{E}}}=\left\|\begin{array}{ll}1 & 0 \\ 0 & 1\end{array}\right\|$ - diagonal unity matrix;

$\mathrm{J}_{\mathrm{p}}=\left\|\begin{array}{l}\dot{\mathrm{J}}_{1} \\ \dot{\mathrm{J}}_{3}\end{array}\right\|$ - column matrix of driving currents;

$\dot{\mathrm{J}}_{1}=0.16+0,05 \mathrm{i} ; \dot{\mathrm{J}}_{3}=6+4,2 \mathrm{i}$ - total currents of cut nodes;

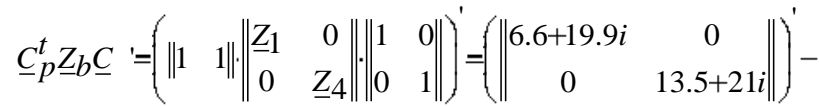
matrix of node resistance of the scheme with respect to the cut nodes with indices (');

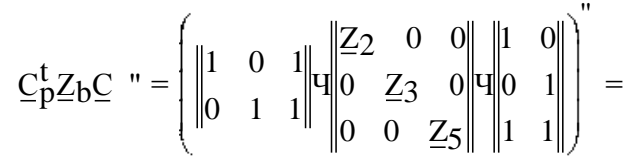

$$
\begin{aligned}
& \left.=\left(\left\|\begin{array}{cc}
23+41.44 \mathrm{i} & 6.8+16.24 \mathrm{i} \\
6.8+16.24 \mathrm{i} & 31.1+54.04 \mathrm{i}
\end{array}\right\|\right)\right)^{\prime \prime}
\end{aligned}
$$

matrix of node resistance of the scheme with respect to the cut nodes with indices (").

$\dot{\mathrm{J}}_{2}=0.27+0,05 \mathrm{i}$-uncut node driving current;

$\dot{\mathrm{U}}_{\Delta \Sigma}=\dot{\mathrm{U}}_{\Delta \mathrm{n}}^{\prime \prime}-\dot{\mathrm{U}}_{\Delta \mathrm{n}}^{\prime}=\left(\left\|\begin{array}{l}1.024+4.725 \mathrm{i} \| \\ 1.024+4.725 \mathrm{i} \|\end{array}\right\|-\left\|\begin{array}{l}0 \\ 0\end{array}\right\|\right)=\left(\left\|\begin{array}{l}1.024+4.725 \mathrm{i} \| \\ 1.024+4.725 \mathrm{i}\end{array}\right\|\right)$

- algebraic sum of nodal voltage drops from currents of uncut nodes;

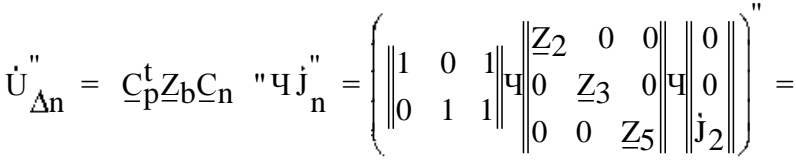

$=\left(\left\|\begin{array}{l}1.024+4.725 \mathrm{i} \\ 1.024+4.725 \mathrm{i}\end{array}\right\|\right)$

$\dot{\mathrm{U}}_{\Delta \mathrm{n}}^{\prime}=\underline{\mathrm{C}}_{\mathrm{p}}^{\mathrm{t}} \underline{\mathrm{Z}}_{\mathrm{b}} \underline{\mathrm{C}}_{\mathrm{n}} \cdot \mathrm{\varphi}_{\mathrm{j}}^{\prime}=$

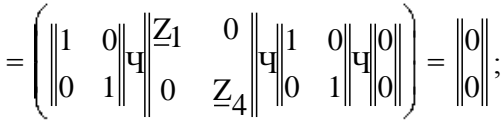

$\underline{C}_{p}^{\prime}=\|1 \quad 1\|, \quad \underline{C}_{p}^{\prime \prime}=\left\|\begin{array}{lll}1 & 0 & 1 \\ 0 & 1 & 1\end{array}\right\|-$ matrix of open circuits

fictitious currents distribution coefficients; 
$\underline{C}_{n}^{\prime}=\left\|\begin{array}{ll}1 & 0 \\ 0 & 1\end{array}\right\|, \quad \underline{C}_{n}^{\prime \prime}=\left\|\begin{array}{ll}1 & 0 \\ 0 & 1 \\ 1 & 1\end{array}\right\|-\quad$ matrixes of distribution coefficients of currents of uncut nodes of subsystems; $\dot{\mathrm{J}}_{\mathrm{n}}^{\prime}=\left\|\begin{array}{ll}0 \\ 0\end{array}\right\|, \quad \dot{\mathrm{J}}_{\mathrm{n}}^{\prime}=\left\|\begin{array}{c}0 \\ 0 \\ \mathrm{~J}_{2}\end{array}\right\|$ - matrixes of the driving currents of uncut nodes of the corresponding subsystems.

If we use the matrix equation (10), then to determine the fictitious currents $\underline{\mathrm{J}}^{\prime \prime}$, we write the formula, which in expanded form looks as:

$$
\begin{aligned}
& \left\|\begin{array}{c}
\dot{\mathrm{j}}_{1}^{\prime \prime} \\
\overrightarrow{\mathrm{j}}_{3}^{\prime \prime}
\end{array}\right\|=-\left\|\begin{array}{cc}
-29.6-61.34 \mathrm{i} & -6.8-16.24 \mathrm{i} \\
-6.8-16.24 \mathrm{i} & -44.6-75.04 \mathrm{i}
\end{array}\right\|^{-1} \mathrm{\Psi} \\
& \mathrm{u}\left\|\begin{array}{c}
1.043+1.184 \mathrm{i} \\
8.224-177.975 \mathrm{i}
\end{array}\right\|=\left\|\begin{array}{l}
-0.468-0.328 \mathrm{i} \\
1.789+1.201 \mathrm{i}
\end{array}\right\|,
\end{aligned}
$$

where

$$
\begin{aligned}
& \underline{\mathrm{Z}}=-\left(\left\|\mathrm{C}_{\mathrm{p}}^{\mathrm{t}} \underline{\mathrm{Z}}_{\mathrm{b}} \underline{\mathrm{C}}_{\mathrm{p}}\right\|\left\|^{\prime \prime}\right\| \mathrm{C}_{\mathrm{p}}^{\mathrm{t}} \underline{\mathrm{Z}}_{\mathrm{b}} \underline{\mathrm{C}}_{\mathrm{p}} \|^{\prime}\right)=\left(\left\|\begin{array}{cc}
\| \underline{\mathrm{Z}}_{2}+\underline{\mathrm{Z}}_{5} & \underline{\mathrm{Z}}_{5} \\
\underline{\mathrm{Z}}_{5} & \underline{\mathrm{Z}}_{3}+\underline{\mathrm{Z}}_{5}
\end{array}\right\|^{\|} \| \begin{array}{c}
\underline{\mathrm{Z}}_{1} \\
0
\end{array}\right. \\
& =\left(\left\|\begin{array}{cc}
-29.6-61.34 \mathrm{i} & -6.8-16.24 \mathrm{i} \\
-6.8-16.24 \mathrm{i} & -44.6-75.04 \mathrm{i}
\end{array}\right\|\right) \text {; } \\
& \dot{\mathrm{U}}_{\Delta \Sigma}=\dot{\mathrm{U}}_{\Delta \mathrm{n}}^{\prime \prime}-\left\|\underline{\mathrm{C}}_{\mathrm{p}}^{\mathrm{t}} \underline{Z}_{\mathrm{b}} \underline{\mathrm{C}}_{\mathrm{p}}\right\|^{\prime} \mathrm{\textrm { }} \dot{\mathrm{J}}_{\mathrm{p}}=
\end{aligned}
$$

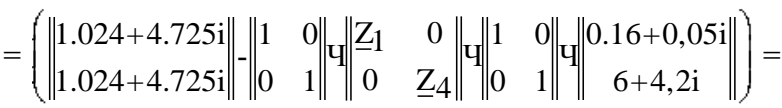

$$
\begin{aligned}
& =\left(\left\|\begin{array}{c}
1.043+1.184 \mathrm{i} \\
8.224-177.975 \mathrm{i}
\end{array}\right\|\right) \text {. }
\end{aligned}
$$

For the remaining unknown currents, the following expression is true:

$$
\begin{aligned}
& \dot{\mathrm{j}}_{\mathrm{p}}{ }^{\prime}=\dot{\mathrm{j}}_{\mathrm{p}}-\dot{\mathrm{j}}_{\mathrm{p}}^{\prime \prime}=\left\|\begin{array}{l}
\mathrm{j}_{1}-\mathrm{j}_{1}^{\prime \prime} \\
\dot{\mathrm{j}}_{3}-\mathrm{j}_{3}^{\prime \prime}
\end{array}\right\|= \\
& =\left\|\begin{array}{c}
0.16+0,05 \mathrm{i} \| \\
6+4,2 \mathrm{i}
\end{array}\right\|-\left\|\begin{array}{l}
-0.468-0.328 \mathrm{i} \\
1.789+1.201 \mathrm{i}
\end{array}\right\|=\left\|\begin{array}{l}
0.628+0382 \mathrm{i} \\
4.211+2.999 \mathrm{i} \|
\end{array}\right\| .
\end{aligned}
$$

As can be seen, the values of fictitious nodal currents obtained by different methods turned out to be equal among themselves.

The analysis of the modes of the source scheme after the determination of fictitious currents at the subsystems intersections nodes, is performed on the basis of calculations of open circuits which matrix of current distribution coefficients are equal to:

$$
\underline{C}_{\mathrm{p}}^{\prime}=\left(\underline{\mathrm{C}}_{\mathrm{p}}^{\prime} \underline{\mathrm{C}}_{\mathrm{n}}^{\prime}\right)=\left\|\begin{array}{lll}
1 & 0 & 0 \\
0 & 0 & 1 \\
1 & 1 & 1
\end{array}\right\| ; \quad \underline{\mathrm{C}}^{\prime \prime}=\left(\underline{\mathrm{C}}_{\mathrm{p}}^{\prime \prime} \underline{\mathrm{C}}_{\mathrm{n}}^{\prime \prime}\right)=\left\|\begin{array}{ll}
1 & 0 \\
0 & 1
\end{array}\right\|
$$

then, the node voltage drops of the scheme of the individual subsystems provided with indices ('and') are defined as:
$\left\|\begin{array}{c}\dot{\mathrm{U}}_{\Delta 1}^{\prime} \\ \dot{\mathrm{U}}_{\Delta 3}^{\prime}\end{array}\right\|=\left\|\begin{array}{cc}6.6+19.9 \mathrm{i} & 0 \\ 0 & 13.5+21 \mathrm{i}\end{array}\right\| \mathrm{u}\left\|\begin{array}{l}0.628+0382 \mathrm{i} \\ 4.211+2.999 \mathrm{i}\end{array}\right\|=\left\|\begin{array}{l}-3.468+15.012 \mathrm{i} \\ -6.118+128.92 \mathrm{i}\end{array}\right\|$;

$\left\|\begin{array}{c}\dot{\mathrm{U}}_{\Delta 1}^{\prime \prime} \\ \dot{\mathrm{U}}_{\Delta 2} \\ \dot{\mathrm{U}}_{\Delta 3}\end{array}\right\|=\left\|\begin{array}{ccc||ccc}1 & 0 & 1\end{array}\right\|\left\|\begin{array}{ccc}16.2+25.2 \mathrm{i} & 0 & 0 \\ 0 & 0 & 1 \\ 0 & 1 & 1\end{array}\right\| \mathrm{\Psi}\left\|\begin{array}{ccc}0 & 24.3+37.8 \mathrm{i} & 0 \\ 0 & 0 & 6.8+16.24 \mathrm{i}\end{array}\right\| \mathrm{\Psi}$

$\mathrm{\Psi}\left\|\begin{array}{ccc||c|c|c}1 & 0 & 1 \\ 0 & 0 & 1 \\ 1 & 1 & 1\end{array}\right\| \mathrm{\Psi} \mid \begin{gathered}0.628+0382 \mathrm{i} \\ 0.27+0,05 \mathrm{i} \\ 4.211+2.999 \mathrm{i}\end{gathered}\|=\| \begin{gathered}-3.468+15.012 \mathrm{i} \\ -4.17+32.115 \mathrm{i} \\ -6.118+128.92 \mathrm{i}\end{gathered} \|$,

where

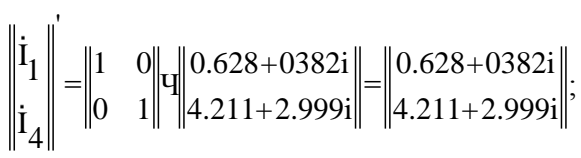

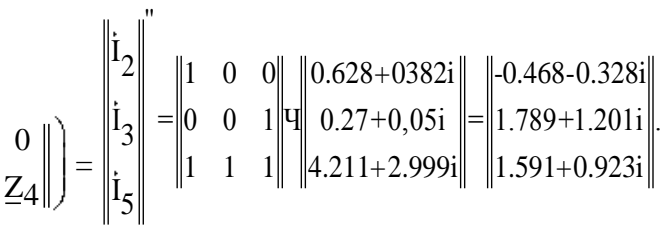

The correctness of the calculations can be verified by the identity conditions for the intersection points:

$$
\left.\begin{array}{l}
\dot{U}^{\prime} \Delta 1=\dot{U}^{\prime \prime} \Delta 1 \\
\dot{U}_{\Delta 3}=\dot{U}^{\prime \prime}{ }_{\Delta 3}
\end{array}\right\}
$$

\section{Conclusions}

1. A method was developed for dividing a system based on the equality of the voltage of the nodes of the subsystems intersection circuits;

2. Nodal voltages of the subsystems intersection circuits are formed directly according to the scheme.

3 . The reduction of a complex closed network to an equivalent open network greatly simplifies the calculation algorithms of its steady-state modes.

\section{References}

1. Kron G. Investigation of complex systems by parts diakoptiks. Nauka, 542 (1972).

2. Gamm A.Z., Glinevich G.A., Krumm L.A. and others. The use of decomposition to solve certain problems and the management of large energy systems. Irkutsk, SOAN SSR, Volume 1. 172-192 (1970)

3. Geraskin O.T. Diakoptics and sparsity of tasks and calculations of large electric energy systems. News of higher educational institutions of the USSR. Power engineering. No.1. 7-12 (1982).

4. Kuzmin Y.F., Makhnitko A.Y. Calculation of electrical grids and given powers of the nodes of the methods of partitioning into subschemes. Electricity. No.5. 16-20 (1972)

5. Makhnitko A.Y. The method of calculating the steady-state mode of the power system in individual subsystems. Electricity. No. 4. 26-30 (1972) 
6. Griben R.M. Topological method of decomposing graphs into parts. Izvestiya/ Energy and transport. 7-10 (1975)

7. Gridin V.N., Anissimov V.I., Atu A.S. Application of the method of diakoptics for modeling and calculating large systems. Control problems. No. 4 (2014)

8. Geraskin O.T. The problem of calculating modes in large electric energy systems and its solution by methods of diakoptics and decomposition, Problems of Energy. No. 1-2. 63-77 (2000)

9. Savina N.V., Tagirov S.V. Decomposition of electrical networks as a means of simplifying the calculation of steady-state modes under market energy conditions. Bulletin of the Amur State University. Series: Natural and economic sciences. No. 43. 60-64 (2008)

10. Khachatryan V.S., Badalyan N.P. Calculation of the steady-state mode of a large electric power system by the method of diakoptics. Electricity. No. 6. 13-17. (2003)

11. Dauren S. Akhmetbayev, Daurenbek A. Aubakir, Yermek Zh. Sarsikeyev, Bakhtybek A. Bainiyazov, Mikhail A. Surkov, Vitaliy I. Rozhkov, Gulbahit N. Ansabekova, Assel S. Yerbolova, Azamat T. Suleimenov, Miramgul S. Tokasheva. Development Of Topological Method For Calculating Current Distribution Coefficients In Complex Power Networks, Results in Physics, 7, 1644-1649 (2017)

12. Akhmetbayev D. Method of calculating the steadystate modes of electrical networks based on the current distribution coefficients. Electricity, No. 11, 23-27, (2010)
13. Dauren Akhmetbayev, Arman Akhmetbayev, Azamat Suleymenov, Michal Kolcun. Modeling the Set Mode of Complex Power Grid, Based on Infeed Coefficients. Proceedings of the 9th International Scientific Symposium, StaráLesná, SlovakRepublic, ELEKTROENERGETIKA, 12.-14, 9 (2017)

14. Akhmetbayev D., Akhmetbayev A., Aidarova A. Determination of the rational transformations distribution networks distribution. E3S Web of conferences 25.04003 (2018).

15. Arman Akhmetbayev, Dauren Akhmetbayev, Serik Zhumazhanov, Bauyrzhan Zhakishev. New Modeling of Steady-State Modes of Complex Electrical Grids of Power Systems MATEC Web of Conferences 155, 01043 (2018)

16. Akhmetbayev D., Akhmetbaev A., Berdygozhin A.S. Topological method for the formation of an inverted form of the node equations of electric energy systems. Electricity, No. 5, (2018)

17. Kholmsky V.G. Calculation and optimization of modes of electrical networks/ High school, 280 (1975) 